\title{
Examining Graduate Student Engagement in Counseling Services with Diverse Populations in P-12 Education
}

\author{
Shyrea J. Minton \\ California State University, Northridge \\ U. S. A.
}

ABSTRACT: Given the continued diversification of P-12 education, it is imperative for professional school counselors to possess multicultural counseling competency in order to effectively engage diverse students in counseling. Thus, it is relevant to examine the preparation of professional school counselors-in-training related to multicultural and social justice counseling competency. This study explores the multicultural counseling competence of five professional school counselors-in-training and offers recommendations for counselor educators teaching cross-cultural counseling courses and coordinating school counselor training programs.

KEYWORDS: cross-cultural counseling, professional school counseling, P-12 education, counselor education, diversity

\author{
Multicultural Counseling Competency \\ Professional School Counseling \\ Method \\ Data Collection and Analysis \\ Findings \\ Discussion and Interpretation \\ Limitations and Future Research \\ Implications \\ Notes \\ References \\ Author Contact \\ Appendix
}

In 2002, Constantine discussed the growing diversity - both racial and ethnic - of schools in cities across the United States. Fourteen years later, this trend continues. As of the 2015-16 academic year, for instance, the enrollment of ethnic minority students in schools in Los Angeles County was $85.77 \%$, compared to $75.9 \%$ across the state (California Department of Education [CDE], 2016). According to data found on the CDE website, in Los Angeles County during the 2015-16 academic school year, student demographics related to race and ethnicity were as follows: $65.06 \%$ Hispanic or Latino; $7.82 \%$ Black or African American, not Hispanic; $7.61 \%$ Asian, not Hispanic; $0.23 \%$ American Indian or Alaska Native, not Hispanic; 0.35\% Native Pacific Islander, not Hispanic; 2.22\% Filipino, not Hispanic; $1.89 \%$ Two or more races, not Hispanic; $0.54 \%$ did not report; and $14.23 \%$ were White, not Hispanic (CDE, 2016). The diversification of the P-12 student 
population supports the notion that education professionals, particularly professional school counselors (PSCs), should be trained to engage diverse students in counseling services. According to the American Counseling Association's [ACA] Ethical Standards (2014), "honoring diversity and embracing a multicultural approach in support of the worth, dignity, potential and uniqueness of people within their social and cultural contexts" (p. 3) is a core professional value of members of the counseling profession. Based on these statistics, it is reasonable to assert that counselors should possess strong multicultural counseling competency, given the growing diversity of schools in cities across this country (CDE, 2016; Constantine, 2002).

The graduate training program from which participants were recruited for this study is one of the original six Transforming School Counseling Initiative (TSCl) universities that focused on increasing the number of ethnic minority school counselors by changing the recruitment and selection processes of school counselor preparation programs to target more ethnic minority groups (Hanson \& Stone, 2002). At the time, there was a lack of ethnic diversity among school counselors, and ethnic minority groups were underrepresented with regard to both counselor education faculty and students in graduate programs (Dinsmore \& England, 1996; Hanson \& Stone, 2002). According to Hanson and Stone, the TSCI universities focused on outreach to attract ethnic minority candidates who possessed skills, attitudes, and knowledge that matched the newly created mission and vision statements of the programs and who had personal and social consciousness skills, as well as the ability to identify inequality in schools and barriers that impeded learning for ethnic minority students.

Despite the efforts of the TSCI, Whites, at $59.24 \%$, continue to make up the majority of students in programs accredited by CACREP (Council for Accreditation of Counseling and Related Educational Programs) in various counseling fields, including school counseling. Ethnic minority groups totaled just over $40 \%$ of students in CACREP-accredited programs in 2016 (CACREP, 2017a). Moreover, per the vital statistics CACREP report, the majority $(73.63 \%)$ of full-time faculty members in CACREP-accredited programs in 2016 were White, while ethnic minority groups made up just over $26 \%$ of the full-time faculty members in CACREP accredited programs (CACREP, 2017a).

I am a core faculty member and one of the coordinators of the graduate school counseling training program at a TSCl university, where the mission of the program is to prepare school counselors who "are driven by a vision for educational equity and excellence to achieve high academic performance and professional competencies...that promote high academic achievement and preparation for success in a 4-year college or university among PreK-12 grade public school students" (Program Mission Statement, 2017). Moreover, the following philosophical themes are embedded throughout the program: social justice, advocacy, leadership, and multicultural awareness (Program Mission Statement, 2017).

Yet, as noted by Feldwisch and Whiston (2015), and Ratts and Hutchins (2009), there is a dearth in the research literature related to whether or not school 
counselors do actually adopt social justice oriented attitudes and behaviors. In addition, there is reason to postulate that insufficient use of social justice oriented attitudes and behaviors by practicing school counselors may have linkage to the counseling preparation program. Given the demographics of P-12 education, it is necessary to examine how preparation programs are training graduate school counseling students to engage with diverse student populations and to understand counseling students' views of their own multicultural counseling competence.

This study of graduate students' experience with cross-cultural counseling evolved from my informal conversations with former second-year graduate students in the program. The students reported that they had not given much thought to cross-cultural counseling engagement with diverse groups since their first semester in the program. Therefore, I explored whether or not students felt safe engaging in cross-cultural counseling in P-12 environments and if students found the "Diversity in Counseling" course content difficult to implement. An additional goal was to identify possible reasons for any self-reported lack of use of culturally responsive strategies during counseling sessions. The purpose of this study was to answer the following research questions:

1. Do students experience roadblocks (e.g., lack of diversity-related programs, lack of support) at their field sites that cause difficulty in counseling engagement with diverse students?

2. Did students find the information offered in the cross-cultural counseling course to be misaligned with their work in schools?

Investigation of these questions has implications for the multicultural counseling competency (MCC) of participants. The next two sections focus on this concept; for the purposes of this paper, multicultural counseling and cross-cultural counseling will be used interchangeably.

\section{Multicultural Counseling Competency}

The Multicultural Counseling Competency (MCC) guidelines, created in response to a request from the president of the Association of Multicultural Counseling and Development (AMCD), were deemed necessary because of the following reasons: (a) increasing diversity of the U.S. population and higher birth rates of certain cultural groups; (b) the increase in counselors self-designating as multicultural counselors with no specific standards in place to judge competence; and (c) the longstanding use of and focus on monocultural frameworks in counselor education (Arredondo, 1999; Sue, Arredondo, \& McDavis, 1992). This focus often prevents counselors from recognizing how their counseling practice, based on monocultural theories primarily developed by White males, may impact culturally diverse groups (Sue, 2004). Chung and Bemak (2012) critiqued that Western psychology regularly places "focus on the individual and their pathology or strengths, rather than the broader social, economic, political, and ecological context" (p. 4). 
The MCC framework included focus in the following areas: (a) counselor awareness of own cultural values and biases; (b) counselor awareness of client's worldview; and (c) culturally appropriate intervention strategies. Within those three overarching areas, there is focus on the following three elements: beliefs and attitudes, knowledge, and skills (Sue et al., 1992). According to Sue and colleagues, when counselors achieve awareness, possess specific knowledge about racial and cultural heritage, and understand how to use relevant research in practice, with regard to themselves and their clients, those counselors may be seen as being multiculturally competent in their practice with clients.

In 2015, the MCCs were revised and are now called the Multicultural and Social Justice Counseling Competencies (MSJCC). The revised framework has been expanded to include intersectionality or focus on how counselors' multiple identities connect to the dynamics of power, privilege, and oppression and how they may influence the counseling relationship (Ratts, Singh, Nassar-McMillan, Butler, \& McCullough, 2015). The term intersectionality, coined by Crenshaw (1991), posited that the experience of oppression and violence by Black women is not an either/or experience-i.e., either racism or sexism—but a both/and experience-i.e., both racism and sexism (also Smith 2009). This groundbreaking work focuses on how our multiple social identities are connected and thus form our unique experiences. Because we bring our unique identities into the counseling session, it is necessary to understand how the dynamics of power, privilege, and oppression have been encountered and explored throughout our development. A likely place for graduate students to examine this is during their counselor preparation program.

Building upon the original MCC framework established by Sue et al. (1992), the new MSJCC framework offers domains aligned with the previous domain areas and also focuses on the developmental nature of the new domain areas and the distinctive layers that may lead to multicultural and social justice counseling competency (Ratts et al., 2015). The four domain areas include (a) counselor selfawareness; (b) client worldview; (c) the counseling relationship; and (d) counseling and advocacy interventions. Just as with the original MCC framework, within the first three domain areas, the MSJCC focus on attitudes and beliefs, knowledge, and skills. However, the new framework offers an additional focus area, action (Ratts et al., 2015). Ultimately, the MCC framework was revised to offer counselors an updated framework with which to implement the MSJCC into counseling theory, practice, and research (Ratts et al., 2015).

Related to implementation, the new framework provides descriptive language for the four domain areas focused on how one's attitudes and beliefs connect to one's knowledge, which connects to one's skills and leads to action. For example, when counselors assess their own self-awareness about their attitudes and beliefs, they acknowledge the following:

Their assumptions, worldviews, values, beliefs, and biases as members of privileged and marginalized groups; their privileged and marginalized status in society; [how] their privileged and marginalized status influences their worldview; [how] their privileged and marginalized status provides 
advantages and disadvantages in society; [and] their openness to learning about their cultural background as well as their privileged and marginalized status. (Ratts et al., 2015, p. 5)

In the above example, counselors seek to assess and increase understanding of their own self-awareness, linked to their attitudes and beliefs, which demonstrates how the MSJCC can be used. After all content in the counselor self-awareness domain is reviewed, focusing on attitudes and beliefs, knowledge, and skills, counselors can then take specific "actions to increase their self-awareness of their social identities, social group statuses, power, privilege, oppression, strengths, limitations, assumptions, attitudes, values, beliefs, and biases" (Ratts et al., 2015, p. 6). Each of the four domain areas offers content that allows the counselor to complete assessments that build awareness and understanding.

The process of self-exploration, however, is time-intensive. When counselors fully engage, they will see how the choice of theory used in counseling, the provision of counseling services with individuals, and the scholarly research (if engaged) can be directly connected to their multicultural and social justice counseling competency. Self-exploration of these topics is typically honed in the graduate training program; thus, it is important to understand if our training methods related to diversity in counseling are effective.

\section{Professional School Counseling in the Context of Multicultural Counseling Competence}

Professional school counselors (PSCs) are charged with addressing academic, social/emotional, and college and career development with P-12 students. Given the increasing diversity of school populations, it is important to address counselors' multicultural counseling competence (Ahmed, Wilson, Henriksen Jr., \& WindWalker Jones, 2011; Holcomb-McCoy, 2005). For the purpose of this paper, professional school counselors-in-training are the focus, along with the skills that school counselors-in-training must possess in order to intervene and counsel a diverse group of students.

According to the American School Counselor Association's (ASCA) ethical standards, as part of the PSCs' responsibility to the school, PSCs should "promote cultural competence to help create a safer more inclusive school environment" (ASCA Ethical Standards, B.2.m, 2016, n.p.) and "use culturally inclusive language in all forms of communication" (ASCA Ethical Standards, B.2.p, 2016, n.p.). Additionally, in their responsibilities to self, PSCs are to "monitor and expand personal multicultural and social-justice advocacy awareness, knowledge and skills to be an effective culturally competent school counselor," and must "understand how prejudice, privilege and various forms of oppression based on ethnicity, racial identity, age, economic status, abilities/disabilities, language, immigration status, sexual orientation, gender, gender identity, expression, family type....affect students and stakeholders" (ASCA Ethical standards, B.3.i, 2016, 
n.p.). There is a clear link between the MSJCC defined previously and the ethical standards for PSCs, which gives credence to the need to understand how school counselors-in-training learn to engage with diverse populations.

Counselor education programs typically offered only one course related to multiculturalism, and these courses often did not include much in terms of consideration of race, culture, or ethnicity (Arredondo, 1999). Moreover, as highlighted by Paisley and McMahon (2001) and Sears and Granello (2002), in addition to the issue of only one course being offered in the training program, many counselors had no education in multicultural counseling and the psychological and educational theories, included as part of the training program, have been primarily developed from the Eurocentric perspective. Further, as asserted by Paisley and McMahon (2001), the inclusion of only one course over one semester, with limited opportunity for further growth and development throughout the counseling program, may "be inadequate in both time and scope to develop culturally competent counselors" (p. 108). At the graduate level, this remains true today; the typical counseling program curriculum includes only one cross-cultural counseling course, a fact discovered through a quick Internet search of graduate counseling training programs nationwide.

Consequently, traditional counselor education focused on didactic and classroom experiential learning may limit the facilitation of understanding of the distinctive needs of diverse communities (Burnett, Hamel, \& Long, 2004). As Lee, Rosen, and McWhirter (2014) assert, using a traditional classroom format for cross-cultural counseling instruction may not allow space for understanding multicultural content on an experiential level. Given the need for understanding of diverse populations, when working as a professional school counselor (Ahmed, et al., 2011; Holcomb-McCoy, 2005), and the increasing diversification of education today, this study explores the perceived multicultural counseling competence of professional school counselors-in-training and their thoughts about the training received in their graduate program. The contextual framework of choice for this study was multicultural counseling competency (MCC).

\section{Method}

A qualitative phenomenological approach was chosen as the method of inquiry for this study. This study is directly relevant to the graduate training program in which I am a core faculty member, and importance was placed on understanding second-year graduate students' common or shared lived experiences (Creswell, 2007), regarding their participation in a graduate crosscultural counseling course and subsequent fieldwork in a school setting after engagement in the course. Also, a phenomenological approach was used because it was important to understand the experiences of several participants, as the outcome of the research study is likely to influence pedagogical practices and curricular content. Through the qualitative phenomenological approach, themes of meaning emerged. In addition, textural and structural descriptions (Creswell, 
2007) were joined to express the essence of difficulties experienced by participants during fieldwork while engaging diverse students in counseling.

To explore graduate students' engagement with diverse P-12 students and experiences in a cross-cultural counseling course, study participants were recruited from a graduate school counseling preparation program at a large urban public university in Southern California. The program is a 55-unit Master of Science in Counseling degree program that holds national accreditation through CACREP and state accreditation with the California Commission on Teacher Credentialing (CTC), the body that credentials school counselors in the state of California. Additionally, students are required to take prerequisite courses prior to entering the program: Educational Psychology or Development and Learning, Fundamentals of Counseling, and Educational Statistics (Educational Psychology \& Counseling, 2017).

Purposive sampling was used to select the participants for this study, as this sampling method involves selecting participants because they are believed to be representative of the subject of study (Gay, Mills, \& Airasian, 2009): in this case, student participants who had completed the cross-cultural graduate counseling course and who were also engaged in fieldwork in a school setting. The total number of second-year students in the program cohort was 17-two males and 15 females. Five females of the 17 cohort members agreed to participate in the study.

Information related to participants' ethnic backgrounds was not collected as part of the demographic information; however, this information was readily available by accessing program data collected during the application process. One participant identified as Chinese (Kate ${ }^{1}$ ), one participant identified as Latina (Ali), one participant identified as Middle Eastern (Zen), and two participants identified as White (Emily \& Lyn). Participants did not disclose their socioeconomic status during the study. Related to age, three participants were in their mid-20s, and two participants were in their mid-to-late-30s.

I believe that the participants held positive attitudes toward the topical focus and openness to discussing diversity-related content. This belief is based on prior conversations with students during the cross-cultural counseling course (Diversity in Counseling) and on engagement with students during other program courses that also included themes of social justice, advocacy, and counseling diverse populations. While these courses were not specifically focused on diversity-related issues, I include in all courses a thread of the themes listed in the previous sentence, which connect in full or in part with the Social and Cultural Diversity Professional Counseling Identity standards included in the 2016 CACREP program standards. The standards are as follows:

a) multicultural and pluralistic characteristics within and among diverse groups nationally and internationally;

b) theories and models of multicultural counseling, cultural identity development, and social justice and advocacy;

c) multicultural counseling competencies; 
d) the impact of heritage, attitudes, beliefs, understandings, and acculturative experiences on an individual's views of others;

e) the effects of power and privilege for counselors and clients;

f) help-seeking behaviors of diverse clients;

g) the impact of spiritual beliefs on clients' and counselors' worldviews; [and]

h) strategies for identifying and eliminating barriers, prejudices, and processes of intentional and unintentional oppression and discrimination. (CACREP, 2017b, p. 9)

\section{Data Collection and Analysis}

After the university's Institutional Review Board (IRB) granted approval for the research study, study participants were recruited from the school counseling graduate program. With the informed consent form in the attachment, an email was sent to students to request participation for a focus group discussion and the completion of a multicultural counseling competency checklist. A focus group discussion was chosen because it was likely to yield good information, as interviewees were similar and cooperative with one another and because time was limited (Creswell, 2007). The focus group session lasted just under 40 minutes. Study participants also completed a multicultural counseling competency checklist for school counselors originally created by Holcomb-McCoy (2004), which was used to understand participants' views of their own multicultural counseling competence.

Prior to completing the checklist and participating in the focus group discussion, participants were given a hardcopy of the informed consent form that had been emailed to them previously, to ensure that study participants completely understood their engagement in the research study and also to allow participants to ask any questions about their participation. Study participants also gave permission to be audio-recorded. There were eight questions (see Table 1) devised to facilitate discussion, in the context of understanding and examining in greater depth study participants' engagement with diverse student populations at their fieldwork sites, any roadblocks they may have experienced, and their thoughts on what they learned in the cross-cultural counseling course that they have used at their field sites with students and/or faculty and staff.

The audio-recorded discussion was transcribed for analysis to identify any thematic meaning related to significant statements made by participants, as well as any emergent patterns. First, I listened to the focus group discussion in its entirety without transcribing. I then returned to the discussion and completed the transcription of the focus group discussion over several days. After the transcription was completed, I then listened to the focus group discussion while reading the transcript to ensure that the transcribed content was accurate. My notes taken of participants' responses were used during the drafting of this paper to provide any added context that may have occurred during the focus group 
discussion (e.g., head nodding by participants, posture, and connection to previous responses from participants).

Table 1

Focus Group Discussion Facilitation Questions

1. Discuss your experiences working with diverse students at your current field site.

2. How would you describe the climate of your field site for diversity related issues?

3. What types of diversity or cross-cultural programs are offered for students and faculty/staff at your current site?

4. Do you feel as though you have been prepared to work with diverse students in $\mathrm{P}-12$ education?

5. Are you comfortable with engaging students in P-12 education around topics of diversity?

6. What did you learn in your Diversity in Counseling course that you have used at your field site with students and/or faculty/staff?

7. What do you believe was lacking from your Diversity in Counseling course?

8. How supported do you feel at your field site to engage in difficult, but necessary, conversation?

The responses on the checklist provided by study participants were also analyzed to determine existing patterns related to the view of competence. Additionally, I engaged in member-checking (Creswell, 2007) after discussion surrounding the eight questions occurred. Specifically, I sought to review with participants the preliminary analyses formed after each question, to ensure that participants' views were accurately noted. This also allowed space for participants to offer additional information that may have been missed.

In phenomenological research, it is important to identify researcher bias from the outset of the study. I believed then, and do now, that graduate school counseling preparation programs are training future PSCs to address issues of cultural awareness and understanding - both on the part of the counselor and the student-along with training that addresses how PSCs can use a social justice approach to counseling when working with P-12 students (see Ahmed et al., 2011; Bryan \& Henry, 2012; Griffin \& Steen, 2010; Holcomb-McCoy, 2007; MooreThomas \& Day-Vines, 2010). Sadly, it is my opinion that the cross-cultural counseling course-taken during my own master's level program-lacked depth and did not facilitate understanding of how to engage with diverse populations in schools. The most relevant experiences came outside of my training program through conference session attendance, continuing education courses, and real 
engagement with diverse students. As a former school counselor turned counselor educator, I am invested in understanding how we are preparing school counselors to engage with diverse populations.

Additionally, it is relevant to note again that I am a core faculty in the graduate training program and had taught the study participants in various courses throughout their program. It is also important to note that I was the faculty for the students' cross-cultural counseling course during their first year in the program. I enjoy teaching this course specifically and often have to engage in self-reflective practices to maintain awareness of biases as a Black woman in the United States and students' bias about me in the cross-cultural counseling course. Moreover, self-reflection is an important part of my preparation for teaching this course, as it is when I review the MSJCC framework to identify and explore feelings related to privilege and oppression as a member of various identity groups. Lastly, as a faculty member in the study participants' program, I was aware of a power dynamic that existed. I attempted to address this at the beginning of the focus group discussion in order to create a safe space to hear and understand participants' experiences in the cross-cultural counseling course and in their experiences at their field sites. As Hayes (2008) noted, power differentials can affect what and how much is shared, and these differences mean that one person is generally in a more vulnerable position and less likely to speak freely. For this reason, at the outset of the discussion session, the power dynamic was addressed, and participants were encouraged to be as open and honest in their responses as possible. Participants were asked to share as much as they were comfortable with sharing. Based on the relationship that I had cultivated with these participants, there was belief that participants would be open and honest during the discussion session.

\section{Findings}

As part of the data collection, participant responses were tracked using a multicultural counseling competency checklist. The checklist is comprised of nine competency domains, with questions in each domain, and graduate students are able to check met or unmet in response to the prompts in each of the domains. The nine domains are as follows:

1. Multicultural counseling;

2. Multicultural consultation;

3. Understanding racism and student resistance;

4. Understanding racial and/or ethnic identity development;

5. Multicultural assessment;

6. Multicultural family counseling;

7. Social advocacy;

8. Developing school-family-community partnerships; and

9. Understanding cross-cultural interpersonal interactions (see Table 2 for checklist). 
Based on participants' responses, participants mainly believed themselves to be competent across the nine domains.

Table 2

Themes - Multicultural Counseling Competency Checklist

\begin{tabular}{|l|l|}
\hline \multicolumn{1}{|c|}{ Domains } & \multicolumn{1}{|c|}{ Ratings } \\
\hline Domain 1: Multicultural counseling & $\begin{array}{l}2 \text { of } 5 \text { participants rated at least } 1 \text { out of } 8 \\
\text { competency areas as unmet in this domain }\end{array}$ \\
\hline Domain 2: Multicultural consultation & $\begin{array}{l}2 \text { of } 5 \text { participants rated at least } 1 \text { out of } 5 \\
\text { competency areas as unmet in this domain }\end{array}$ \\
\hline $\begin{array}{l}\text { Domain 3: Understanding racism } \\
\text { and student resistance }\end{array}$ & $\begin{array}{l}4 \text { of } 5 \text { participants rated at least } 2 \text { out of } 9 \\
\text { competency areas as unmet in this domain* }\end{array}$ \\
\hline $\begin{array}{l}\text { Domain 4: Understanding racial } \\
\text { and ethnic identity development }\end{array}$ & $\begin{array}{l}3 \text { of } 5 \text { participants rated at least } 1 \text { out of } 3 \\
\text { competency areas as unmet in this domain }\end{array}$ \\
\hline $\begin{array}{l}\text { Domain 5: Multicultural } \\
\text { assessment }\end{array}$ & $\begin{array}{l}\text { All participants rated at least } 1 \text { out of } 6 \\
\text { competency areas as unmet in this domain }\end{array}$ \\
\hline $\begin{array}{l}\text { Domain 6: Multicultural Family } \\
\text { Counseling }\end{array}$ & $\begin{array}{l}1 \text { of } 5 \text { participants rated at least } 1 \text { out of } 5 \\
\text { competency areas as unmet in this domain }\end{array}$ \\
\hline Domain 7: Social Advocacy & $\begin{array}{l}2 \text { of } 5 \text { participants rated at least } 1 \text { out of } 8 \\
\text { competency areas as unmet in this domain }\end{array}$ \\
\hline $\begin{array}{l}\text { Domain 8: Developing school- } \\
\text { family-community (SFC) } \\
\text { partnerships }\end{array}$ & $\begin{array}{l}4 \text { of } 5 \text { participants rated at least } 1 \text { out of } 3 \\
\text { competency areas as unmet in this domain }\end{array}$ \\
\hline $\begin{array}{l}\text { Domain 9: Understanding cross- } \\
\text { cultural interpersonal interactions }\end{array}$ & $\begin{array}{l}3 \text { of } 5 \text { participants rated at least } 1 \text { out of } 5 \\
\text { competency areas as unmet in this domain }\end{array}$ \\
\hline
\end{tabular}

* 4 of 5 participants rated the same competency skill in this Domain as unmet. While 4 of 5 participants also rated an additional skill in Domain 3 as unmet, there was no uniformity present between participants in terms of the second skill they deemed to be unmet.

While all participants rated at least one competency area as unmet in Domain 5 and 4 of 5 participants rated at least one competency area as unmet in Domain 8, participants' responses to competency skill areas in these domains were scattered. In Domain 5, there was not one competency skill that more than 3 of 5 participants checked as being unmet. The skill that 3 of 5 participants believed they lacked was, "I am able to use test information appropriately with culturally diverse students." It is understandable that participants would find this competency skill absent, considering the lack of focus placed on using test information in counseling sessions with P-12 students. While there is focus in the course on how testing practices can be inequitable for students in P-12 education 
(see Hartney \& Flavin, 2014; Hursh \& Martina, 2003), concrete strategies for including this information in counseling sessions with students or parents are not provided.

Specific to Domain 8, 3 of 5 participants checked as unmet the competency skill "I have developed a school-family-community (SFC) partnership team or some similar type of group that consists of community members, parents, and school personnel." While students do receive content in their cross-cultural counseling course that addresses how to establish and maintain SFC partnerships, students in the past have shared that they believed they lacked the time to thoroughly engage in the creation of these partnerships and shared discomfort in suggesting that SFCs be established at their school sites (this view has been captured outside of this focus group discussion). SFCs are considered to be a best practice in school counseling and are viewed as an effective means to combat achievement discrepancies experienced by many ethnic minority students (Bryan, 2005; Griffin \& Steen, 2010; Holcomb-McCoy, 2007), yet students did not find value in using this intervention.

Despite the scattered responses highlighted just above, Domain 3 will be highlighted in the following section, as 4 of 5 participants rated at least two competency areas in this domain as unmet. After sharing findings related to Domain 3 of the checklist and discussion questions (DQs), there will be exploration of students' experiences in the cross-cultural counseling course, and any areas that participants' believed to be lacking in the course.

\section{Multicultural Competence Checklist Domain 3 Connected with DQs}

With regard to Domain 3, Understanding racism and student resistance, participants acknowledged a lack of inclusion of race-related information in classroom guidance lessons and regular counseling activities with students. While 4 out of 5 participants checked the competency skill "I understand the relationship between student resistance and racism" as met, 4 out of 5 participants also checked unmet for the competency skill "I include topics related to race and racism in my classroom guidance units." Given that $80 \%$ of study participants indicated they understood the relationship between student resistance and racism and yet $80 \%$ did not include topics related to racism in their classroom guidance units, the question "why" springs to mind. I considered that a potential reason for this was because students did not feel comfortable working with students in P-12 education around diversity-related topics, or they may have felt uncomfortable bringing these topics forward at their site, or perhaps they did not receive support from their school site supervisors. Based on participants' responses to discussion questions (DQs) 3,5 , and 8 , it appears the answer to "why" participants did not include topics related to race and racism in their classroom guidance units is related to participants' nervousness and discomfort with bringing these topics forward, which connects to a lack of diversity-related programming at the site, despite their feelings of being prepared and comfortable with engaging P-12 students directly around topics of 
diversity. The following responses to $\mathrm{DQs} 5,8$, and 3 highlight participants' beliefs about their levels of comfort, their thoughts about support at the field site, and diversity programming at their sites:

\section{DQ 5: Are you comfortable with engaging students in P-12 education around topics of diversity?}

Ali: "I...feel comfortable speaking to students regarding oppression and reduction issues, um, my only issue or concern would be students interpreting it wrong, and hopefully me delivering the message correctly is my biggest concern, and also perhaps students like again perceiving it wrong and saying it to their parents in a wrong way, in a way that I probably didn't want it to come out to be that way, and it may come off that way. So that's my only concern, in K-12, you have to be more sensitive and um, very careful with your words."

Emily: "Yes, I feel comfortable, I love any chance I can get to talk about diversity-related issues, I feel what [Ali] says, there is some concern that the kids or students might, you know, form an opinion about it and take it home to their parents and tell them their opinion and then say that it's what I had said. Um also another concern is that I...if I were to have a diversity-related presentation or discussion with some students, I would be nervous about how some students might react...is it inappropriate either towards each other or make some sort of insensitve remark...how that might make me feel, I would have to learn how to control my feelings about it, where in my personal life, I might want to be like, how dare you say something like that, you bluh bluh bluh, um, especially if it's a culture that maybe I belong to, or if I have close friends that are a part of, but I, I jump at the chance to talk about diversity issues."

Although two of the four participants highlighted that they felt comfortable engaging with students-evidenced by statements and head nodding amongst the participants-they also discussed their nervousness regarding how their messages may be interpreted or translated to students' parents. This had not been a discussion topic in the cross-cultural counseling course. Working with parents specifically is reviewed in another course within the graduate students' training program. These responses highlight a slight disconnect between theory and practice, given that one cannot work as a school counselor with students without working with their families or guardians. The main focus of the cross-cultural counseling course is working with students of diverse backgrounds and engaging school site stakeholders, such as faculty, staff, and administrators. Given the participants' concerns about parents' possible reactions, it seems necessary to incorporate more formal training in the cross-cultural counseling course that is focused on working with parents as well.

DQ 8: How supported do you feel at your field site to engage in difficult, but necessary, conversations?

Ali": "Um, I feel very supported in the sense that specifically at [work"] I have received oppression and reduction training over like 5 times, um, 
through the residential life housing and student housing here at [university]. Um, that's a very strong emphasis during that summer that we take pride in, um, so I feel very supported when it comes to [university] and talking about these issues here versus, if it [is] like an educational space, because I feel like, and I've said this before, this is the place to really talk about issues and have discussions with students who probably are unaware or afraid or not comfortable in talking about any type of oppression reduction issues that they might probably experience or that are going on. Um, I feel very supported at this school specifically. Other schools, like [fieldwork site] and other schools like other sites that I'm at, I'm kind of hesitant, because I don't know what kind of background or what training they have received, as far as these topics, and I am nervous to speak up in that sense. But I know that if something triggers it, I will speak up, um, but you know, a lot of people that l've worked with at my site are much older and that's, and they're very traditional I feel, and they've said some comments where I'm like maybe this is not the right time, but if there's that right time, I will speak up."

Lyn: "I feel very supported at my site, I think um because l've noticed that um, that people are very attentive, um as far as treating students, very, um, I mean not perfectly I wouldn't say, but I feel like that environment is there, that climate is there, where they try to support students in different ways to have that comfort for all the students, um, so because I see that they treat their students that way, I feel that I would be comfortable, and there would be the support. So the staff is very multicultural, and I haven't experienced I've mainly experienced very positive outlook from them. I feel like they look at their students on a very level field.

Emily: "Um at the high school, I don't think I would feel comfortable or supported if I wanted to present my own you know program or project, or some sort of initiative with relation to diversity awareness or anything like that because, I can't give any real concrete examples, but it just feels to me as though this high school is a, kind of a, approaches it as like a colorblind approach, where everyone is, let's treat everyone the same, everyone is equal, it doesn't matter um what color you are and this and that, what ethnicity you are, um, and so that's just the feeling that I get, so I feel as though I might cause some tension if I were to bring up doing some sort of program like that...

While two participants expressed that they felt comfortable with initiating programs focused on diversity content, if needed (only one quote shown), the other three participants shared feelings of hesitancy and potential resistance and tension from their sites in general to implement diversity-related programming (two quotes shown). This was seen in my notes where leg shaking and fidgeting were noted as some participants answered this question. In the cross-cultural counseling course, programs are explored that can be used at a school site level to bring about a more inclusive school culture (e.g., the Cultural Awareness Learning Module issued by the U.S. Department of Labor; programming offered by Teaching Tolerance; and other relevant programming). However, in that course, there is not 
a focus on navigating the school site as a school counselor-in-training, where there is a power dynamic. Here again, there seems to be a slight disconnect between what we are teaching in the program, and the practice that our school counselorsin-training are engaging in at their field sites. How do graduate students bring forth an idea to address an issue when they believe the climate of the site to be questionable regarding diversity awareness? How do you begin the conversation when there is a dearth of diversity-related programming present at the site (highlighted in participants' responses to DQ 3; see below)? The lack of formal programming, coupled with the difficulty of navigating the field site as a school counselor-in-training, highlights a need for the cross-cultural course to include methods to initiate difficult dialogues.

DQ 3: What types of diversity or cross-cultural programs are offered for students and faculty/staff at your current site?

Ali: "Recently I noticed there was a cultural cooking class, and that was surprising to me to see at the high school level because I don't see any clubs that are advertised. I don't even know if there are any clubs that deal with diversity, whether it's race/gender, and that was really interesting for me to notice because I don't know if the students asked for that cultural cooking class, or if that was the idea of the teacher to provide that to the students...because from my understanding, well from my experience when I took the cooking class, he did do a lot of dishes from different cultures, and again, I don't know how that was brought up."

Kate: "At my high school, we have culture week, and every day is a different country, and they do whatever activities are relevant to that country, so for example, if it was Europe or America, they had the fencing club out because fencing was big in monarchy countries, and then like for Asia they played $K$-pop during lunch and they had different activities related to the type of country, so it's really awesome to see that. And they had a banner in their quad of all of the different flags from all over the world."

Lyn: "At my site it's kind of similar to what's been presented, as far as there's no formal education...it's all through activities and clubs, and it's basically the students' choice if they want to learn or not. So the same type of setting that has been described.

\section{Exploration of Cross-cultural Counseling Course Experiences}

To highlight study participants' experiences in their cross-cultural counseling course, discussion questions (DQs) 6 and 7 were used to elicit participants' experiences working with diverse students and implementing, if any, any of the cross-cultural counseling course content with students, faculty, and staff, at their field sites. Based on participants' responses during discussion, participants seemed to find value in the course content and highlighted areas they believed would strengthen the course and their ability to connect course content information 
with their real world work as school counselors. Participant responses to DQs 6 and 7 are included below.

\section{DQ 6: What did you learn in your Diversity in Counseling course that you have used at your field site with students and/or faculty/staff?}

Ali: "I think a big thing for me, is um, being open-minded in that sense that um, there's so many backgrounds and generations, I feel that, I think that my supervisor is always constantly saying, be open-minded, and just try to be comfortable in your setting, if not try to, you know, if you need assistance, always seek for help, and consult, is always the um, the things that my supervisor has always advised for me, I think that I can agree with what she does."

Lyn: "What I learned was um ...uh, White people, some people don't um, at the student level, the White privilege concept, they don't understand that. They don't recognize the privileges that they have, and how some of those privileges oppress others. So working with a student population, I think is a good age to introduce that for them to understand that before they become so set in their ways. Because l've also noticed with many adults, it's hard to change. So I learned that that's an important avenue to address."

Zen: "What I learned in that class I would say, um, that I use today is the language that I use. I think I'm more aware of um, not um, just being more mindful of who l'm talking to, like for example, not saying like, you guys to address everyone, you know... if there are females in the group. It's just like the language I think I'm more aware of, um and, or saying something like, even something like, you know someone just came from another country, and telling them like oh, but your English is really good. Like I think, in the past I don't think I realized that that was being insensitive, but I do remember learning that, and that's something l've been more aware of. And I came across someone who did say that to someone, and I did see the other person's reaction was they were kind of like taken aback and I recognize um, that it is offensive, and the other person didn't even realize that that had hurt them. So just definitely, I would say my language has been more mindful."

Emily: "Also with the language, I'm more aware of my language too. Um around students and teachers and parents. Um, and I learned from the course, one of the things that has really stuck with me is just constantly checking in with myself and checking in with my biases, trying to be careful that when I'm working with students, that any sort of stereotype that might creep into my mind while l'm in a session with them, to be aware of that and not try to not let it influence our communication, and l've also come to understand um a lot more about the systemic approach, that just because a student is not doing their homework, maybe a few years ago, I would have just said something like you didn't do your homework, well, you know, you have to do it, whereas now, there [are] many different reasons for students not doing their homework that might not be their fault. So I'm a lot less 
regimented about you gotta do this, and you gotta do that. So um because I was a substitute teacher, I wasn't coming from a counselor standpoint, it was more like where's your homework, where's this, but now, I'm not, I don't judge, I just try to help the student, and l'm always checking my own biases and prejudices."

Participants highlighted that they have used some of the course content in their work with students, faculty, and staff at the field site, such as the ability to be open-minded, the need to address White privilege, and remaining aware of the language that is used when interacting with individuals from diverse backgrounds-all concepts reviewed in the cross-cultural counseling course. A thread found in participants' responses is a focus on self-awareness, e.g., regularly identifying how they perceive and engage students.

\section{DQ 7: What do you believe was lacking from your Diversity in Counseling course?}

Kate: "I honestly don't think anything was lacking, I learned so much. Um, just about every race, every culture, um, you know and it wasn't just hitting on it at, here's this race, here's what people think about this, it was in depth. Everything was so in depth, I don't think that I was lacking anything, because everything was just so eye-opening.

Emily: "I would say that yea, it was great. I learned so much. Um, if we did go over this, then I obviously forgot it. I would just probably, you know, say that um, I feel like when um, when people hear about diversity or culture, or cultural differences, that their mind, even though I know we went over it a bunch of different cultures, but I feel as though it's very specifically focused on race and ethnicity differences. Even though in the class we did go over gender and sexism, and LGBTQ, and all that, I still feel like maybe just talking about the fact that culture is many different types of identities, just maybe take that and expand that a little more, um, just in my day to day life, even I start thinking that different cultures means different ethnicity. Well no, that's not true, so yeah, maybe just expanding on that a little."

Emily's point here about highlighting different types of identities connects to the need to incorporate added focus in the course on intersectionality addressing how multiple social identities connect and may influence the experiences of students in P-12 education. While Emily identified that there was a focus on other identities, e.g., gender, sexism, and LGBTQ identity, it is clear from her response that this aspect should be strengthened.

Ali: "I think it already has [been] mentioned, we did go over a lot of information, and it's heavy information as well, so processing it is, you know, it takes some time. I do remember an activity that we did that was, kind of like, it was like, a step-in kind of circle, I think that in itself painted the big picture for some people, as far as you know where people stand, and seeing that with our cohort, um, and I think that touched a lot of people in a way, that I felt like if we would have done more of those little activities where it's like moving around and actually experiencing what it does for you and 
seeing other people's like face reactions and body language, I think that um, that can also be very helpful."

Kate (again): "I think also bringing in real world experiences, especially now with, you know with all the cops and all that (participant did not expand beyond this). That was one of my favorite parts, was just seeing what we were learning then and there and seeing how it relates to real life now.

Lyn: "I think if I'm not wrong, we did one assignment as uh, regarding where we checked off where we summed up where we were, where we summed up who we are, like it was ageism, if you're between 45 and whatever, sexism, we did that assignment in the book."

Lyn is referring to the ADDRESSING assignment that students complete in the course. Students respond to each area (Age and generational influences; Developmental disabilities; Disabilities acquired later in life; Religion and spiritual orientation; Ethnic and racial identity; Sexual orientation; Socioeconomic status; Indigenous heritage; National origin; and Gender [Hayes, 2008]) to recognize and understand the influence of various sociocultural contexts/identities within and the impact of these contexts on their work as counselors. This is a tool used to begin students on the journey of self-exploration, while fostering self-awareness.

Lyn (cont.): "That was great, I think it needed to go a little deeper, so to give students a little more opportunity to maybe do like a self-reflection as a homework, so they could just dig a little deeper, because things like that I think don't just come out, I think you need to really search within yourself to see where you stand and what you think, and what you believe. So yeah, I think that assignment, maybe something like that would be a little more beneficial."

Participant responses align with Lee et al. (2014), as they identified that using a traditional classroom format for cross-cultural counseling instruction may not allow space for understanding multicultural content on an experiential level. Based on participants' responses, it is apparent that more experiential activities, deeper engagement with some of the content, and more real world experience would have been beneficial to study participants, in both the classroom environment and in real world settings. Additionally, added focus on the multiple social identities/contexts of both P-12 students and graduate students would better connect course content with the MSJCC framework, thereby potentially enhancing graduate students use of this framework when working with P-12 students.

\section{Discussion and Interpretation}

The focus of this study was to examine graduate counseling students' experiences working with diverse populations at their fieldwork school sites. The essence captured through the textural descriptions provided by participants included the following broad strokes: (a) Participants experienced comfort in engaging P-12 students on race-related topics, including topics of oppression and 
reduction issues individually, yet noted a lack of certainty in suggesting schoolwide programming on these topical areas; and (b) Participants shared general concerns about how parents would perceive information received second-hand. With regard to the structural description, participants felt unsupported at field sites to engage in diversity-related conversations/programming. Specifically, for participants who had given thought to bringing forward some type of programming, participants noted that they lacked supportive allies-site supervisors or other stakeholders at the field site-to facilitate the inclusion of these topics into the general school environment, and were hesitant and concerned about potential tension and resistance from individuals at their sites.

These findings answer the two questions posed at the outset of the study. First, do students experience roadblocks (e.g., lack of diversity related programs, lack of support) at their field sites that cause difficulty in counseling engagement with diverse students? The answer is affirmative, based on discussion with study participants. Graduate students have experienced roadblocks at their sites due to lack of formal diversity-related programming and lack of perceived support to engage P-12 students in diversity issues. This was made clear by participants' responses to the discussion questions related to how supported they felt to engage in difficult yet necessary conversations and what types of cross-cultural programs were offered for students and faculty/staff at their field sites. Additionally, several participants highlighted their hesitancy, feelings of nervousness, and concern over creating tension by suggesting an implementation of diversity programming, which showcases the need to include more course content focused on helping students initiate difficult dialogues as school counselors-in-training.

With respect to the second question, "Did students find the information offered in the cross-cultural counseling course to be misaligned with their work in schools?" the answer was negative. While participants highlighted specific areas related to course content that could be strengthened, participants shared that they found the course beneficial overall. However, there appears to be a need to focus more on the real-world work of school counselors that graduate students will engage in routinely during their day, such as navigating relationships with parents of diverse students, to ensure that instances of miscommunication or misinterpretation are minimized, and navigating the field site as a school counselor-in-training.

As shown in the findings section, the current cross-cultural counseling course does not focus on working with parents or families; hence, it was not surprising that study participants expressed nervousness or anxiety in having parents misinterpret something that was stated by the counselor to the student, and then later shared with the parent by the student. If there were more content specific to working with parents and families in the cross-cultural counseling course, this might prove to be a non-issue going forward. Additionally, more focus on experiential activities, real world experiences, and the intersection of multiple group identities is needed, as highlighted by participants in their responses to discussion question 7. A greater focus on the intersection of the multiple identities of the graduate student and P-12 students might foster an enhanced connection 
to the MSJCC framework, ultimately moving graduate students toward greater multicultural counseling competence.

This information is relevant as we consider counselor education and preparation programs. Given that site supervisors at fieldwork sites must meet specific qualification requirements, one of which is to have two years of experience as professional school counselors (CACREP, 2017c) before they are eligible to supervise school counselors-in-training, it becomes clear how the gap between theory and practice can persist. Because the graduate student participants in this study will one day likely become site supervisors, it is relevant to ensure that graduate students establish a clear understanding of diversity and culturally related counseling content while in their graduate training programs. This is necessary so that when they become professional school counselors, they are well prepared to provide a safe and supportive environment for future professional school counselors-in-training who are exploring diversity issues in their work with P-12 students.

\section{Limitations and Future Research}

There are several limitations to this study. First, the study sample included only five graduate counseling students. Given the large number of individuals enrolled in graduate counseling programs across the country, the findings of this limited study are not generalizable. While this was not the intent of this study, the purpose of which was to explore a specific phenomenon that had implications for the graduate counseling program in which the study participants were enrolled, it is relevant to note this as a limitation. Secondly, all study participants were female; this limited the chance to explore if perceived lack of support could be explained by assertiveness differences between males and females (see Leaper \& Robnett, 2011). Lastly, socioeconomic status and other identities of participants were not collected as part of this study. This is a limitation, considering the newly introduced emphasis on intersectionality in the revised MSJCC framework, because the dynamics of power, privilege, and oppression may influence the counseling relationship (Ratts et al., 2015). Thus, it would be relevant to understand participants' view of their own group identities and how these might impact their work with diverse student populations.

Future studies should explore the engagement of graduate counseling students around topics of diversity-related issues and their engagement with P-12 students on a larger scale. Perhaps a longitudinal study could examine multiple cohorts_including a significant number of both males and females-over a number of years to explore the competence of graduate students in the areas just noted. An added focus would be the exploration of site supervisors' increased comfort in facilitating and supporting engagement of professional school counselors-in-training around these topics. This would be a relevant focus for tracking graduate students who have critically engaged in their programs around diversity-related topics/issues, who have become site supervisors themselves and 
who are responsible for providing supervision to professional school counselorsin-training.

\section{Implications}

Despite the limitations reviewed previously, I advocate for the exploration of graduate students' perceptions about their engagement with P-12 students around diversity-related topics. This is key to consider as we explore the divide between theory and practice, while examining the Multicultural and Social Justice Counseling Competencies (MSJCC) as a framework that not only informs our counseling theory, practice, and research (Ratts et al., 2015), but also moves us away from the use of monocultural frameworks when counseling diverse individuals. To minimize the disconnect that is often seen between theory and practice, counselor educators must remain attuned to changes in the field and also to the practicality of information taught to graduate students to be used in the field. As Davis (2006) noted, because counselor educators are away from the everyday practice of school counseling, counselor educators' perceptions about the daily experiences of school counselors can be skewed. What counselor educators should strive to prevent is the creation of highly enlightened graduate students who can theorize various aspects of school counseling exceptionally well, yet are ill prepared to do the work of professional school counselors. Studies such as the one described in this paper are relatively simple ways to examine school counseling graduate preparation programs beyond students' course/program evaluations and can provide a means to concentrate on specific and relevant areas of the program, such as graduate school counseling students' engagement with P12 students cross-culturally.

Given that the U.S. population continues to diversify and that, as Lee et al. (2014) assert, using a traditional classroom format for cross-cultural counseling instruction may not allow space for understanding multicultural content on an experiential level, a recommendation for school counselor educators is to use adaptive strategies and frameworks such as the MSJCC in their engagement with graduate students. This will both counter the monocultural nature of counseling preparation and also ensure that professional school counselors-in-training are prepared to promote cultural responsiveness in school settings to create an inclusive school culture.

\section{Notes}

1. All names of participants are pseudonyms.

2. Ali works at the university where the graduate training program of focus is located. 


\section{References}

Ahmed, S., Wilson, K. B., Henriksen Jr., R. C., \& WindWalker Jones, J. (2011). What does it mean to be a culturally-competent counselor? Journal for Social Action in Counseling and Psychology, 3(1), 17-27. Retrieved from http://www.psysr.org/jsacp/ahmed-v3n1-11_17-28.pdf

American Counseling Association. (2014). 2014 ACA code of ethics. Retrieved from http://www.counseling.org/docs/ethics/2014-aca-code-of-ethics.pdf ?sfvrsn=4

American School Counselor Association. (2016). ASCA ethical standards for school counselors. Retrieved from https://www.schoolcounselor.org/asca/ media/asca/Ethics/EthicalStandards2016.pdf

Arredondo, P. (1999). Multicultural counseling competencies as tools to address oppression and racism. Journal of Counseling \& Development, 77(1), 102108. doi: 10.1002/j.1556-6676.1999.tb02427.x

Bryan, J. (2005). Fostering educational resilience and academic achievement in urban schools through school-family-community partnerships. Professional School Counseling, 8, 219-227. Retrieved from http://www.jstor.org/ stable/42732462

Bryan, J., \& Henry, L. (2012). A model for building school-family-community partnerships: Principles and process. Journal of Counseling and Development: JCD, 90, 408-420. doi: 10.1002/j.1556-6676.2012.00052.x

Burnett, J. A., Hamel, D., \& Long, L. L. (2004). Service learning in graduate counselor education: Developing multicultural counseling competency. Journal of Multicultural Counseling and Development, 32(3), 180-191. doi: 10.1002/j.2161-1912.2004.tb00370.x

California Department of Education. (2016). Enrollment by ethnicity for 2015-16 [Data file]. Retrieved from http://dq.cde.ca.gov/dataquest/Enrollment/Ethnic Enr.aspx?cChoice $=$ CoEnrEth\&cYear $=2015-16 \&$ TheCounty $=19$, LOS $\% 5$ EANGELES\&cLevel=County\&cTopic=Enrollment\&myTimeFrame=S\&cTyp $\mathrm{e}=\mathrm{ALL} \& \mathrm{cGender}=\mathrm{B}$

Chung, R. C., \& Bemak, F. (2012). Social justice counseling: The next steps beyond multiculturalism. Thousand Oaks, CA: Sage.

Constantine, M. G. (2002). Racism attitudes, White racial identity, attitudes, and multicultural counseling competence in school counselor trainees. Counselor Education \& Supervision, 41(3), 162-174. doi: 10.1002/j.15566978.2002.tb01281.x

Council for Accreditation of Counseling \& Related Educational Programs (CACREP). (2017a). Annual report 2016 [Data file]. Retrieved from http://www.cacrep.org/about-cacrep/publications/cacrep-annual-reports/ 
Council for Accreditation of Counseling \& Related Educational Programs (CACREP). (2017b). Section 2: Professional counseling identity. Retrieved from http://www.cacrep.org/section-2-professional-counseling-identity/

Council for Accreditation of Counseling \& Related Educational Programs (CACREP). (2017c). Section 3: Professional practice. Retrieved from http://www.cacrep.org/section-3-professional-practice/

Crenshaw, K. (1991). Mapping the margins: Intersectionality, identity politics, and violence against women of color. Stanford Law Review, 43(6). 1241-1299. doi: $10.2307 / 1229039$

Creswell, J. W. (2007). Qualitative inquiry \& research design: Choosing among five approaches. Thousand Oaks, CA: Sage.

Davis, T. E. (2006). Looking forward to going back: A school counselor educator's return to school counseling. Professional School Counseling, 10(2), 217223. doi: http://dx.doi.org/10.5330/prsc.10.2.ykh7p1404r121k58

Dinsmore, J. A., \& England, J. T. (1996). A study of multicultural counseling training at CACREP-accredited counselor education programs. Counselor Education \& Supervision, 36(1), 58-76. doi: 10.1002/j.15566978.1996.tb00236.x

Educational Psychology \& Counseling. (2017). Pre-approved Undergraduate Course Substitutions for EPC Prerequisites for the Program. Retrieved from http://www.csun.edu/eisner/educational-psychology-counseling/preapproved-undergraduate-course-substitutions

Feldwisch, R. P., \& Whiston, S.C. (2015). Examining school counselors' commitments to social justice advocacy. Professional School Counseling, 19(1), 166-175. doi: https://doi-org.libproxy.csun.edu/10.5330/1096-240919.1.166

Gay, L. R., Mills, G. E., \& Airasian, P. (2009). Educational research: Competencies for analysis and applications. Upper Saddle River, NJ: Pearson Education, Inc.

Griffin, D., \& Steen, S. (2010). A social justice approach to school counseling. Journal for Social Action in Counseling and Psychology, 3(1), 74-85. Retrieved from http://www.psysr.org/jsacp/griffin-v3n1-11_74-85.pdf

Hanson, C., \& Stone, C. (2002). Recruiting leaders to transform school counseling. Theory into Practice, 41(3), 163-168. Retrieved from http://www.jstor.org/ stable/1477237?seq=1\&cid=pdf-reference\#fndtn-references_tab_contents

Hartney, M. T., \& Flavin, P. (2014). The political foundations of the Black-White achievement gap. American Politics Research, 42(1), 3-33. doi: https://doi.org/10.1177/1532673X13482967

Hayes, P. (2008). Addressing cultural complexities in practice: Assessment, diagnosis, and therapy. Washington, DC: American Psychological Association. 
Holcomb-McCoy, C. (2007). School counseling to close the achievement gap: A social justice framework for success. Thousand Oaks, CA: Corwin Press.

Holcomb-McCoy, C. (2005). Investigating school counselor' perceived multicultural counseling competence. Professional School Counseling, 8(5), 414-423. Retrieved from http://libproxy.csun.edu/login?url=http://search. ebscohost.com/login.aspx?direct=true \&db=aph\&AN=17402987\&site=ehos t-live

Holcomb-McCoy, C. (2004). Assessing the multicultural competence of school counselors: A checklist. Professional School Counseling, 7(3), 178-186. Retrieved from http://www.jstor.org/stable/42732560?seq=1\#page_scan_ tab_contents

Hursh, D., \& Martina, C. A. (2003). Neoliberalism and schooling in the US: How state and federal government education policies perpetuate inequality. Journal of Critical Education Policy Studies, 1(2), 31-52. Retrieved from http://www.jceps.com/wp-content/uploads/PDFs/01-2-02.pdf

Leaper, C., \& Robnett, R. C. (2011). Women are more likely than men to use tentative language, aren't they? A meta-analysis testing for gender differences and moderators. Psychology of Women Quarterly, 35(1), 129142. doi: $10.1177 / 0361684310392728$

Lee, D. L., Rosen, A. D., \& McWhirter, J. J. (2014). Assessing changes in counselor trainees' multicultural competence related to service learning. Journal of Multicultural Counseling and Development, 42, 31-41. doi: 10.1002/j.2161-1912.2014.00042.x

Moore-Thomas, C., \& Day-Vines, N. L. (2010). Culturally competent collaboration: School counselor collaboration with African American families and communities. Professional School Counseling, 14, 53-63. doi: http://dx.doi.org/10.5330/prsc.14.1.0876387q7466x634

Paisley, P. O., \& McMahon, H. G. (2001). School counseling for the twenty-first century: Challenges and opportunities. Professional School Counseling, 5, 106-115. Retrieved from http://www.jstor.org.libproxy.csun.edu/stable/ 42732325

Program Mission Statement (2017). Retrieved from http://www.csun.edu/eisnereducation/educational-psychology-counseling/ms-school-counseling

Ratts, M. J., Singh, A. A., Nassar-McMillan, S., Butler, S. K., \& McCullough, J. R. (2015). Multicultural and social justice counseling competencies. Retrieved from https://www.counseling.org/docs/default-source/competencies/ multicultural-and-social-justice-counseling-competencies.pdf?sfvrsn=20

Ratts, M. J., \& Hutchins, A. (2009). ACA advocacy competencies: Social justice advocacy at the client/student level. Journal of Counseling \& Development, 87, 269-275. doi:10.1002/j.1556-6678.2009.tb00106

Sears, S. J., \& Granello, D. H. (2002). School counseling now and in the future: A reaction. Professional School Counseling, 5(3), 164-171. Retrieved from 
http://libproxy.csun.edu/login?url=http://search.ebscohost.com/login.aspx? direct=true \&db=aph\&AN=6124160\&site=ehost-live

Smith, S. (2009). Black feminism and intersectionality. International Socialist Review, 91. Retrieved from http://isreview.org/issue/91/black-feminismand-intersectionality

Stone, C., \& Hanson, C. (2002). Selection of school counselor candidates: Future directions at two universities. Counselor Education and Supervision, 41(3), 175-192. doi: 10.1002/j.1556-6978.2002.tb01282.x

Sue, D. W. (2004). Whiteness and ethnocentric monoculturalism: Making the invisible visible. American Psychologist, 59(8), 761-769. doi: 10.1037/0003066X.59.8.761

Sue, D. W., Arredondo, P., \& McDavis, R. J. (1992). Multicultural counseling competencies and standards: A call to the profession. Journal of Counseling \& Development, 70(4), 477-486. doi: 10.1002/j.1556-6676.1992.tb01642.x

\section{Author Contact}

Shyrea J. Minton: shyrea.minton@csun.edu

California State University-Northridge, Educational Psychology and Counseling, 18111 Nordhoff St, Northridge, CA 91330-8265 


\section{Appendix}

\section{School Counselor Multicultural Counseling Competency Checklist}

From: Holcomb-McCoy, C. (2004). "Assessing the multicultural competence of school counselors: A checklist," Professional School Counseling, 7(3), 178-186. (reprinted with permission)

\section{APPENDIX}

School Counselor Multicultural Competence Checklist

COMPETENCE

\section{Multicultural Counseling}

1. I can recognize when my attitudes, beliefs, and values are interfering with providing the best services to my students.

2. I can identify the cultural bases of my communication style.

3. I can discuss how culture affects the help-seeking behaviorsof students.

4. I can describe the degree to which a counscling approach is culturally inappropriate for a specific student.

5. I use culturally appropriate interventions and counseling approaches (e.g., indigenous practices) with students.

6. I can list at least three barriers that prevent ethnic minority students from using counseling services.

7. I can anticipate when my helping style is inappropriate for a culturally different student.

8. I can give examples of how sterotypical beliefs about culturally different persons impact the counseling relationship.

\section{Multicultural Consultation}

9. I am aware of how culture affects traditional models of consultation.

10. I can discuss at least one model of multicultural consultation.

11. I recognize when racial and cultural issues are impacting the consultation process.

12. I can identify when the race and/or culture of the client is a problem for the consultee.

13. I discuss issues related to race/ethnicity/culture during the consultation process, when applicable.

III. Understanding Racism and Student Resistance

14. I can define and discuss White privilege.

15. I can discuss how I (if European American/White) am privileged based on my race.

16. I can identify racist aspects of educational institutions.

17. I can define and discuss prejudice.

18. I recognize and challenge colleagues about discrimination and discriminatory practices in schools.

19. I can define and discuss racism and its impact on the counseling process.

20. I can help students determine whether a problem stems from racism or biases in others.

21 I understand the relationship between student resistance and racism.

22. I include topics related to race and racism in my classroom guidance units. 


\section{APPENDIX \\ School Counselor Multicultural Competence Checklist (continued)}

COMPETENCE

IV. Understanding Racial and/or Ethnic Identity Development

23. I am able to discuss at least two theories of racial and/or ethnic identity development.

24. I use racial/ethnic identity development theories to understand my students' problems and concerns.

25. I have assessed my own racial/ethnic development in order to enhance my counseling.

\section{v. Multicultural Assessment}

26. I can discuss the potential bias of two assessment instruments frequently used in the schools.

27. I can evaluate instruments that may be biased against certain groups of students.

28. I am able to use test information appropriately with culturally diverse parents.

29. I view myself as an advocate for fair testing and the appropriate use of testing of children from diverse backgrounds.

30. I can identify whether or not the assessment process is culturally sensitive.

31. I can discuss how the identification of the assessment process might be biased against minority populations.

\section{Multicultural Family Counseling}

32. I can discuss family counseling from a cultural/ethnic perspective.

33. I can discuss at least two ethnic group's traditional gender role expectations and rituals.

34. I anticipate when my helping style is inappropriate for an ethnically different parent or guardian.

35. I can discuss culturally diverse methods of parenting and discipline.

\section{Social Advocacy}

36. I am knowledgeable of the psychological and societal issues that affect the development of ethnic minority students.

37. When counseling, I consider the psychological and societal issues that affect the development of ethnic minority students.

38. I work with families and community members in order to reintegrate them with the school.

39. I can define "social change agent."

40. I perceive myself as being a "social change agent."

41. I can discuss what it means to take an "activist counseling" approach.

42. I intervene with students at the individual and systemic levels.

43. I can discuss how factors such as poverty and powerlessness have influenced the current conditions of at least two ethnic groups. 


\section{APPENDIX}

\section{School Counselor Multicultural Competence Checklist (continued)}

COMPETENCE

Met

VIII. Developing School-Family-Community Partnerships

44. I have developed a school-family-community partnership team or some similar type of group that consists of community members, parents, and school personnel.

45. I am aware of community resources that are available for students and their families.

46. I work with community leaders and other resources in the community to assist with student (and family) concerns.

\section{Understanding Cross-Cultural Interpersonal Interactions}

47. I am able to discuss interaction patterns that might influence ethnic minority students' perceptions of inclusion in the school community.

48. I solicit feedback from students regarding my interactions with them.

49. I verbally communicate my acceptance of culturally different students.

50. I nonverbally communicate my acceptance of culturally different students.

51. I am mindful of the manner in which I speak and the emotional tone of my interactions with culturally diverse students. 